Horizontes. Revista de Investigación en Ciencias de la Educación

ISSN 2616-7964

Julio-septiembre, 2017

HORIZONTES

Volumen 1, Número 3

www.revistahorizontes.org

pp. $42-52$

\title{
La seguridad ciudadana, medios de comunicación y valores de consumo en Venezuela
}

\section{Citizen security, media and consumer values in Venezuela}

Luisa Fernanda Zambrano D.

ferzambranod_mgt@gmail.com

Recibido: 17-10-2016 / Revisado: 20-10-2016 / Aceptado: 20-11-2016 / Publicado: 10-07-2017

RESUMEN

Este artículo se acerca a la problemática social de la seguridad ciudadana desde una mirada que vincula los datos de vulnerabilidad social, con valores del consumismo con los que la población juvenil e infantil se socializa. Hoy los medios de comunicación globales socializan desde la cuna a una población infantil favoreciendo una condición trasnacional, estereotipada, occidentalizada, consumista y fragmentada, acostumbrándola a altos niveles de calidad gráfica y dinámica, a altos ritmos y excesos de emocionalidad y saturación de sentidos, factores que pudiesen estar contribuyendo a facilitar el desarrollo de ciertas conductas sociales vinculadas a la violencia y su cultura 0 subcultura, dirigida a satisfacer las "necesidades del consumo de todo tipo" sin asumir verdaderas responsabilidades, con poca capacidad para afrontar en primera persona la realidad, con obligaciones y dispuestos a sacrificarse para construir algo duradero y colectivo. Ante esto la tarea de los facilitadores y maestro es la de asumir la educomunicación critica y activa.

Palabras clave: Medios de comunicación, Educación, Jóvenes, Violencia, Inseguridad, Vulnerabilidad Social, Consumo

\begin{abstract}
This article approaches the social problematic of citizen security from a perspective that links the data of social vulnerability, with values of consumerism with which the youth and children are socialized. Today the global media socialize from the cradle to a child population favoring a transnational, stereotyped, westernized, consumerist and fragmented condition, accustoming it to high levels of graphic and dynamic quality, at high rates and excesses of emotionality and saturation of senses, factors That could be contributing to facilitate the development of certain social behaviors linked to violence and its culture or subculture, aimed at satisfying the "needs of all types of consumption" without assuming real responsibilities, with little capacity to face reality in the first person, With real obligations and willing to sacrifice themselves to build something lasting, and collective.
\end{abstract}

Key words: Youth, Violence, Insecurity, Social Vulnerability, Consumption and the Media 


\section{INTRODUCCIÓN}

En Venezuela y toda Latinoamérica son los jóvenes (13 a 25 años), en especial los varones, los que están principalmente involucrados en los actos violentos tanto como víctimas o victimarios de los conflictos armados, robos, hurtos, secuestros, bandas o pandillas y de todos los delitos vinculados a la desigualdad y el desempleo. Es está población, la principal protagonista de la cultura violenta que reflejan los procesos de marginación, inequidades, frustraciones, desamor, desesperanzas, la imposibilidad de proyectarse, la falta de horizontes, la falta de políticas públicas claras y de canales participativos entre otros sentimientos conflictivos.

La influencia de los medios de comunicación y la crisis valorativa condicionan a los adolescentes y jóvenes, a asumir como principios los contravalores de la cultura de la violencia, orientando su comportamiento a la reproducción del estilo de vida del antihéroe, siendo que la gran industria global mediática convierte, la espectacularidad de las acciones delictivas, las ejecuciones en la vía pública, los atentados, los "Pranes" de cárceles, las balaceras y la crueldad, en los protagonistas épicos de las generaciones jóvenes. La admiración por los hombres y mujeres que encarnan lo prohibido se transforma en "representaciones sociales", que a decir de Moscovici designan "un corpus organizado de conocimientos y una de las actividades psíquicas, gracias a las cuales los hombres hacen inteligible la realidad física y social, se internan en un grupo o en una relación cotidiana de intercambios, liberan los poderes de su imaginación." (Moscovici, 1979: 18).

Estas "representaciones sociales" que los grupos jóvenes tienen de la prosperidad y vida de los narcos, se difunden a través de los medios de comunicación como símbolos de la autonomía económica, valorizada a través de imágenes, programas de atracción como telenovelas y demás fenómenos televisivos y musicales que alimentan los imaginarios colectivos de artistas y trovadores que reproducen en forma de rap, corridos, vallenatos, tecno-cumbias; el basamento de subculturas, concepto que también posee alcances heurísticos que permite trabajar la especificidad de los códigos y símbolos que se imponen en la nueva cartografía social latinoamericana. (Cajas, 2008, Cerna 2002).

Son múltiples los factores que inciden en el aumento y establecimiento de la cultura de la violencia entre ciertas comunidades e individuos para hacerlos más o menos vulnerables a cometer delitos. Estos factores se clasifican en dos subgrupos:

- Los que atañen directamente al individuo: desintegración y violencia familiar, deserción escolar, desempleo, frustración, adicciones, marginalidad, uso de drogas, tenencia de armas, descomposición social, etc.

- Los que atañen al ambiente en que ocurre en delito: presencia policial, vigilancia privada o control social informal, utilización de espacios públicos, iluminación, etc.

\section{Seguridad Ciudadana y Socialización de la Violencia}

La violencia y la inseguridad, constituyen uno de los principales problemas que aquejan a la población venezolana en general y a los jóvenes en particular, ya sea que se recurra a indicadores objetivos (tasa de homicidios, robos, etc.) o subjetivos (estudios de percepción). En tal sentido, evidenciamos que la violencia se hace presente como algo natural en el convivir cotidiano, en la casa, la escuela, la comunidad, la televisión, los videos juegos, las canciones, entre otros. La violencia no sólo se ve asociada a conductas delictuales, en el ámbito comunitario, se expresa como déficit de convivencia entre vecino. Las fórmulas violentas son la manera como se están enfrentando los problemas y conflictos 
de la cotidianidad, la naturalización de la violencia en todos los ámbitos, (niños, jóvenes, adultos hombres y mujeres) están generando altos niveles de inseguridad, ante los cuales ni la comunidad organizada, los Consejos Comunales (vía auto-regulación) o el Estado (vía regulación externa) parecen tener mecanismos de precautelación.

Todo parece señalar que la violencia se está socializando como un modo de convivencia "normal" entre jóvenes y adultos, hombres o mujeres, un pequeño ejemplo puede ser el hecho de llamar a alguien "marico" hasta ayer era un grave insulto que ponía en duda la masculinidad de un caballero, es hoy la forma cotidiana de nombrarse, tan común que es usada tanto por hombre y mujeres que lo utilizan indistintas y repetidas veces en una sola frase de conversación. Son muchos los ejemplos que podemos citar donde algún tipo de violencia que se inicia por lo general en forma verbal, y cada vez va tomando diferentes expresiones para llenar la cotidianidad de casas, escuelas, comunidades, programas televisivos y recreación. La violencia se va socializando para ir siendo aceptadas en espacios públicos $\mathrm{y}$ privados $\mathrm{y}$ donde las instituciones que tienen la responsabilidad de ejercer control y persuasión parecen debilitadas o desinteresadas en asumir dicho Rol.

\section{Cuadro No. 1}

\section{Situaciones de violencia y conflictos en las comunidades}

\begin{tabular}{|l|l|}
\hline Problemas & (\%) \\
\hline 1. Peleas entre vecinos & 16,80 \\
\hline 2. Venta de drogas & 10,91 \\
\hline 3. Problemas en fiestas, matinés, reuniones & 9,39 \\
\hline 4. Alto volumen de los equipos de sonido & 7,74 \\
\hline 5. Violencia entre jóvenes/bandas & 6,34 \\
\hline 6. Problemas por el lugar para botar la basura & 6,34 \\
\hline 7. Uso inadecuado de las vías públicas & 5,89 \\
\hline 8. Peleas por razones políticas & 4,86 \\
\hline 9. Problemas con policías & 4,28 \\
\hline 10. Peleas por venta de alcohol & 4,20 \\
\hline
\end{tabular}

Fuente: Centro de Estudios Sociales (CES): Estudio Caracterización de la Violencia, Criminalidad e Inseguridad en Caracas: perspectiva comunitaria, 2009

Así vemos en el cuadro №1, cifras que confirman lo que venimos señalando, la violencia es parte de la cotidianidad de nuestras comunidades siendo las peleas entre vecinos relacionadas a múltiples factores de la vida doméstica (problemas de basura, escombró, inadecuado uso de espacios comunes, ruidos altos, entre otros), que van escalando niveles de violencia aderezadas siempre por la presencia de drogas y alcohol que agudizan la conflictividad.
En tal sentido, interesa manejar el concepto de prevención del delito; que es entendido como "toda acción orientada a evitar que el delito ocurra, promoviendo y fortaleciendo la seguridad no sólo a través del sistema formal de justicia criminal, sino que también a través de la promoción e implementación de estrategias que involucran a los diferentes sistemas informales de prevención, como los colegios, instituciones 
religiosas y ciudadanía en general" (ONU 2000).

El sistema educativo es visto aquí como sistemas informales de prevención pero todos los involucrados en el aparato educativo debemos asumirnos como principales involucrados en la prevención y entender que como facilitadores de procesos de aprendizaje, también estamos jugamos un importante papel en la modelación y construcción colectiva de los espacios de seguridad y convivencia y no solo pensarnos como invitados de palo, viendo los toros desde la barrera. El mismo llamado, aplica para las instituciones religiosas que al decir de Briceño León (2012); "la religión -en particular la católica-, ha perdido en las zonas urbanas el papel normativo que le permitía ejercer su función de control social...la ley de Dios se ha desvanecido, ha perdido fuerza y capacidad discursiva..." (pág. 35), de ser la afirmación del autor una realidad, esta pudiese estar afectando a más del $60 \%$ de la población venezolana que se declaran como católicos romanos, aunque afirman no participar en las actividades de la iglesia.

\section{Dimensiones del problema de seguridad en la población joven}

Como venimos refiriendo, los contextos sociales venezolanos sobre todo los urbanos han venido acrecentando su vulnerabilidad social ante la victimización, sin embargo, debemos afirmar el problema real que tenemos los investigadores del área debido a la falta de publicación de datos a través de fuentes oficiales, que dificultan el manejo de datos recientes, no obstante, trabajamos con las últimas publicaciones oficiales $\mathrm{y}$ estimaciones publicadas por fuentes no oficiales pero investigadores reconocidos en el área.

Por tanto, trabajamos con la encuesta de victimización cuya última publicación oficial fue en 2009, esta encuesta sirve para determinar los niveles de victimización de un grupo social, para medir el volumen $y$ características de los hechos delictivos cometidos durante un período de tiempo, en una determinada localidad. Esta encuesta estima la cifra negra cero (0) de la delincuencia, es decir, aquellas que no son registradas por organismos oficiales dado a que no son denunciadas. Y también registra un dato subjetivo sobre el miedo de la población a ser víctima de delitos.

La inseguridad y la violencia tal y como se viene registrando produce vulnerabilidad social ante la victimización, entendida esta, como la posible afectación que tiene una persona o grupo social para la ocurrencia de delitos contra su persona o sus bienes, esta vulnerabilidad tiene múltiples factores interrelacionados e interdependientes que puede caracterizarse de acuerdo a:

- Condición demográfica de edad, sexo, estado físico/psíquico.

- Condición situacional o de oportunidad (tiempo-horarios, espacio-lugares); (posesión de armas, tráfico de drogas y alcohol en las comunidades).

- Condición material y económica (pobreza, desempleo, exclusión).

- Condiciones socio-culturales y mediática para la naturalización de la violencia y el delito (convivencia ciudadana y grupos de pertenencia).

- Condiciones institucionales de impunidad y corrupción policial.

Al respecto una muestra de ello, de acuerdo a la encuesta de victimización 2009, los homicidios, lesiones y hurtos se cometen entre un $60 \%$ a un $70 \%$, en la zona de residencia de la víctima. La violencia interpersonal directa, representada por lesiones y homicidios, se encuentra asociada a la nocturnidad, fuera de las horas de trabajo. La nocturnidad también resulta muy asociada al uso de armas de fuego, exceptuando los robos en los cuales se utiliza indistintamente de la hora. La impunidad y corrupción policial también son factores que influyen en los niveles de vulnerabilidad. 
Cuadro No. ${ }^{\circ} 2$

Los delitos con mayor frecuencia de ocurrencia en Venezuela 2010

\begin{tabular}{|l|l|l|}
\hline Delito & Total & $\%$ \\
\hline Hurto & 34.874 & 14 \\
\hline Robo de auto & 27.977 & 11 \\
\hline Violencia Contra la mujer y familia & 26.218 & 10 \\
\hline Robo & 25.855 & 10 \\
\hline Lesiones personales & 23.596 & 9 \\
\hline Posesión de droga & 17.590 & 7 \\
\hline Homicidio & 13.080 & 5 \\
\hline Hurto de auto & 11.336 & 4 \\
\hline Estafa & 10.288 & 4 \\
\hline Robo de moto & 8.562 & 3 \\
\hline 10 Delitos & & 77 \\
\hline
\end{tabular}

Fuente: Datos tomados de la Memoria y cuenta del MPPRIJ 2011

Estos delitos, dan cuenta del $77 \%$ del total de delitos conocidos o denunciados por el CICPC. Es de observar, en cuanto a los delitos con mayor incidencia (hurto, robo de auto, violencia contra la mujer y la familia, robo, lesiones personales y homicidios), la mayoría suponen el uso de la violencia. Del mismo modo, llama la atención el alto porcentaje de ocurrencia de violencia contra la mujer y la familia, hoy denunciada ante las autoridades como un delito, siendo hasta hace poco considerado, parte de un fenómeno cultural que por ende era naturalizado y desestimada su denuncia y penalización.

\section{Cuadro No. 3}

Caracterización de las Victimas

\begin{tabular}{|l|l|l|l|l|l|l|} 
Delitos & Hombres & Mujeres & $\begin{array}{l}\text { Edad } \\
\text { 0 a 14 }\end{array}$ & $\begin{array}{l}\text { Edad } \\
\mathbf{1 5} \text { a 24 }\end{array}$ & $\begin{array}{l}\text { Edad } \\
\text { 25 a 44 }\end{array}$ & $\begin{array}{l}\text { Edad } \\
\text { +de 45 }\end{array}$ \\
\hline Homicidios & $81 \%$ & $19 \%$ & $2 \%$ & $37 \%$ & $44 \%$ & $17 \%$ \\
\hline Lesiones & $56 \%$ & $44 \%$ & $4 \%$ & $23 \%$ & $42 \%$ & $31 \%$ \\
\hline Robos & $62 \%$ & $38 \%$ & $1 \%$ & $18 \%$ & $45 \%$ & $30 \%$ \\
\hline
\end{tabular}

Fuente: Datos extraídos de la Encuesta de Victimización 2009. INE

En cuanto a las víctimas, el cuadro $\mathrm{N}^{\circ} 3$, muestra el resumen de los 3 delitos de mayor ocurrencia en la que se involucran acciones violentas (entendiendo que el hurto es el delito más común, aunque este no es considerado como tal, ya que no implica situaciones de violencia), el tipo de víctima y sus edades, corroborándose lo que venimos señalando, que las víctimas son mayoritariamente hombres jóvenes de entre 15 a 30 años, de todos los delitos especialmente el de los homicidios, al delito de lesiones se le suman las mujeres afectadas por la violencia de pareja e intrafamiliar, ya que la encuesta no discrimina este aspecto, igualmente son las mujeres las que sufren los delitos sexuales. Respecto a los niveles socioeconómicos de las víctimas, las cifras nos señalan que provienen mayoritariamente de los sectores más pobres, es decir, los estratos IV y V. Solo en los delitos de estafa y secuestro los afectados son principalmente de los estratos II, III y IV, la clase más alta no reporta casi ningún tipo de victimización. En lo referido al delito de homicidios, este es el delito más violento dado que implica la perdida de la vida de un ser humano, el Estudio Caracterización de la Violencia, 
Criminalidad e Inseguridad en Caracas (2009), muestra (Ver cuadro $\mathrm{N}^{\circ} 4$ ), que en los municipios que comprenden la zona metropolitana (Baruta, Chacao, El Hatillo, Libertador y Sucre), las primeras dos causas de homicidios, están vinculadas a la venganza entre bandas, ajuste de cuenta entre delincuentes $\mathrm{y}$ las deudas por drogas, situaciones cruzadas por la vida delictual y una tercera y tal vez la más grave situación, dado que supone la pérdida de vidas de personas inocentes ajenas al conflicto, son las muertes por balas perdidas, que afectan a vecinos de las zonas populares donde frecuentemente se presentan los enfrentamientos entre delincuentes.

\section{Cuadro No. 4}

Principales causas de los homicidios (Porcentaje)

\begin{tabular}{|c|c|c|c|c|c|c|}
\hline Los homicidios ocurren por: & 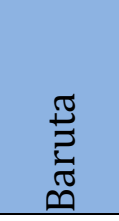 & 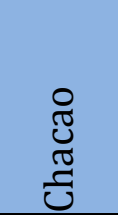 & 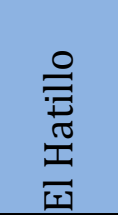 & 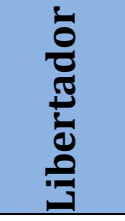 & $\begin{array}{l}0 \\
\stackrel{0}{0} \\
\text { ज }\end{array}$ & 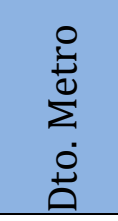 \\
\hline $\begin{array}{l}\text { Venganza entre bandas/ ajuste de } \\
\text { cuentas }\end{array}$ & 34,35 & 19,64 & 38,89 & 30,97 & 27,91 & 30,34 \\
\hline $\begin{array}{l}\text { Riñas y peleas entre familiares } y \\
\text { conocidos }\end{array}$ & 5,34 & 5,36 & 0,00 & 6,68 & 4,88 & 6,03 \\
\hline Riñas y peleas & 13,74 & 16,07 & 8,33 & 7,31 & 13,95 & 9,51 \\
\hline Deudas de drogas & 15,27 & 8,93 & 13,89 & 14,39 & 16,98 & 14,86 \\
\hline Para ganar prestigio como poderoso & 6,87 & 1,79 & 0,00 & 4,01 & 5,81 & 4,47 \\
\hline Como medida para "limpiar" la zona & 3,05 & 1,79 & 0,00 & 2,59 & 2,33 & 2,49 \\
\hline Accidentes al jugar con armas de fuego & 2,29 & 5,36 & 0,00 & 1,10 & 2,33 & 1,56 \\
\hline Deudas de juego y apuestas & 1,53 & 7,14 & 2,78 & 3,14 & 1,40 & 2,75 \\
\hline Peleas entre parejas & 0,00 & 5,36 & 8,33 & 3,54 & 3,72 & 3,48 \\
\hline Para sobrevivir y salvarse uno mismo & 3,05 & 7,14 & 8,33 & 1,97 & 3,26 & 2,60 \\
\hline Por encargos & 9,16 & 8,93 & 11,11 & 7,00 & 5,58 & 6,96 \\
\hline Por balas perdidas & 3,82 & 7,14 & 2,78 & 10,38 & 7,21 & 8,99 \\
\hline Por hacerse del territorio & 0,76 & 1,79 & 0,00 & 5,27 & 3,95 & 4,47 \\
\hline Resistencia al robo & 0,76 & 3,57 & 5,56 & 1,65 & 0,70 & 1,51 \\
\hline
\end{tabular}

Fuente: Centro de Estudios Sociales (CES): Estudio Caracterización de la Violencia, Criminalidad e Inseguridad en Caracas: perspectiva comunitaria, 2009

La encuesta de victimización del 2009, muestra que los victimarios son en su mayoría jóvenes varones de entre 15 a 25 años, que actúan en dúos o tríos para cometer sus delitos, los delitos mayoritariamente se ejecutan en las zonas de residencia de las víctimas, se destaca que en un importante número de homicidios (30\%), el victimario tiene algún tipo de relación interpersonal con su víctima. 
Cuadro No. 5

Caracterización de los Victimarios

\begin{tabular}{|l|l|l|l|l|l|l|}
\hline Delitos & Hombres & Mujeres & $\begin{array}{l}\text { Edad } \\
\text { 0 a 14 }\end{array}$ & $\begin{array}{l}\text { Edad } \\
\mathbf{1 5} \text { a 24 }\end{array}$ & $\begin{array}{l}\text { Edad } \\
\mathbf{2 5} \text { a 44 }\end{array}$ & $\begin{array}{l}\text { Edad } \\
+ \text { de 45 }\end{array}$ \\
\hline Homicidios & $78 \%$ & $22 \%$ & $3 \%$ & $25 \%$ & $70 \%$ & $2 \%$ \\
\hline Lesiones & $86 \%$ & $14 \%$ & $2 \%$ & $28 \%$ & $62 \%$ & $8 \%$ \\
\hline Robos & $90 \%$ & $10 \%$ & $2 \%$ & $60 \%$ & $37 \%$ & $1 \%$ \\
\hline
\end{tabular}

Fuente: Datos extraídos de la Encuesta de Victimización 2009. INE

Por su parte, Briceño León (2012); investigador venezolano, caracteriza a los victimarios como hombres, jóvenes (de 15 a 25 años), que poseen estudios básicos, generalmente pobres, osados, audaces y no les importa la vida. Señala que entre estos grupos de jóvenes se manejan códigos de honor y defensa propia, que generan procesos crecientes de homicidios por relaciones de "amistad", venganza, porque le quitaron la novia, porque lo miraron mal y al final, por dinero. Briceño, además, identifica la intencionalidad de redimirse, como presente entre estos jóvenes, hecho que nos puede hacer pensar, en la falta de oportunidades, la ausencia de espacios "protegidos" para la experimentación juvenil de estos, hoy victimarios, al no tener opciones o alternativas, les tocó decidir por el contexto violento que lamentablemente ofrecen las comunidades más pobres, por otra parte, esta intensión de redimirse asoma la probabilidad de cambio, de búsqueda de alternativas hacia una vida distinta, espiritual, situación que exploran los movimientos cristianos de fe, con sus actividades dentro de las comunidades caraqueñas.
Si bien la subcultura de la violencia latinoamericana es principalmente varonil, las niñas, adolescentes y mujeres no solo son víctimas de abuso sexual, maltrato, discriminación, torturas y asesinato; sino que cada vez tienen mayor participación, como parte activa en el transporte de droga, la ejecución de asaltos, homicidios, etc., siempre en un número menor, pero es significativo igualmente el incremento de la violencia entre las mujeres más jóvenes. En la subcultura de la violencia, la mujer tiene un "objeto", rol fundamental en la exacerbación hedonista del consumo, la re-significación del cuerpo femenino genera la apoteosis de las cirugías plásticas para agrandar el busto o los glúteos, adaptándolo a una nueva categoría estética impuesta por el mundo del espectáculo para ser consumidas y valorizadas por las jóvenes y adolescentes.

El nivel socio-económico de las víctimas, nos ratifica el hecho de que la subcultura de la violencia afecta principalmente a las clases populares, es decir, a los más pobres, tal y como se muestra en el cuadro resumen $\mathrm{N}^{\circ} 6$.

\section{Cuadro No. 6}

\section{Victimización por Nivel Socioeconómico}

\begin{tabular}{|l|l|l|l|l|l|}
\hline \multicolumn{1}{|c|}{ Delitos } & \multicolumn{1}{c|}{ I } & \multicolumn{1}{c|}{ II } & \multicolumn{1}{c|}{ III } & \multicolumn{1}{c|}{ IV } & \multicolumn{1}{c|}{ V } \\
\hline Homicidios & $2 \%$ & $2 \%$ & $12 \%$ & $57 \%$ & $27 \%$ \\
\hline Lesiones & $0 \%$ & $0 \%$ & $16 \%$ & $52 \%$ & $22 \%$ \\
\hline Robos & $3 \%$ & $14 \%$ & $23 \%$ & $50 \%$ & $10 \%$ \\
\hline
\end{tabular}

Fuente: Datos extraídos de la Encuesta de Victimización 2009. INE 
Si nos ubicamos dentro del método de medición de la pobreza utilizada por el Dr. Hernán Méndez Castellano (1959), que utiliza el INE y se emplea para clasificar a la población en cinco niveles: Estrato I: clase alta (4 a 6 puntos), Estrato II: clase media alta (7 a 9 puntos), Estrato III: clase media (10 a 12 puntos), Estrato IV: pobreza relativa (13 a 16 puntos), Estrato V: pobreza crítica (17 a 20 puntos). Estratos sociales que se ajustan de acuerdo al puntaje obtenido en relación con cuatro (4) variables: a) Procedencia del ingreso, b) Profesión del Jefe de Hogar, c) Nivel de instrucción de la madre, c) Condiciones de alojamiento.

Vemos, entonces, que la mayoría de las víctimas en Venezuela, provienen de los niveles de pobreza crítica y relativa, siendo en su mayoría jóvenes provenientes de hogares sin ingresos fijos, con poco nivel de instrucción por parte de su ascendencia, con muy baja o sin calificación profesional y que habitan en espacios con condiciones de precariedad. Descripción que nos permite pensar en ambientes de alta vulnerabilidad social, donde los conflictos y la violencia son parte de la cotidianidad. Igualmente, de estos datos se puede descifrar, que si bien la percepción sobre inseguridad y el miedo parece estar en todos los estratos y rincones del país, la situación se presenta casi confinada a los sectores populares, es un problema principalmente intra clase, no entre clases, y se desarrolla principalmente en los espacios de habitabilidad, donde se establecen "círculos de delitos" (relaciones vinculadas al consumo de drogas, el narcotráfico, las apuestas, la prostitución, entre otras), no es un problema que afecta a todos de la misma manera porque si bien afecta a personas inocentes y ajenas al conflicto (siempre en menor cuantía), es un problema localizado que debe ser abordado entendiendo su justa dimensión.

\section{Consumo comunicacional}

En lo que respecta al consumo comunicacional, con los procesos de globalización se han gestado cambios en las pautas que suponen una segmentación $y$ diferenciación cultural cada vez más próxima a las capacidades de pago familiares, la diversificación de la ofertas editoriales, los nuevos canales especializados, temáticos 0 para audiencias específicas, el desarrollo de la televisión de pago, la informática doméstica, etc., pautas que definen el mercado comunicacional latinoamericano, dominado a su vez, por grandes grupos transnacionales que controlan la oferta y comercialización de buena parte de la mercancías culturales que se dinamizan a través de amplios movimientos de capital (compra, fusiones, absorciones) y empresas con altas tasas de beneficio y pautas de consumo que implican ofertas simbólicas globales, universalizadas, con tendencias a la privatización, desregulación y liberalización de los mercados, locales especialmente del mercado de las tecnologías comunicacionales.

Hidalgo Toledo (2011) explica que los medios, son el eje central de un moderno modelo de comunicaciónmercado/comunicación-poder, más allá de su función de servicio público, ya que el espacio público mediático funciona divorciado de las necesidades del cuerpo social promoviendo el espectáculo, el consumo, los deportes y la información light; lejos de un proyecto de comunicación nacional para la creación de ciudadanía y el fortalecimiento de la democracia. Nos encontramos ante un fuerte desequilibrio social y mediático. No existe un sistema de pesos y contrapesos políticoideológicos ni institucionales. Los medios, en su afán de capitalizar a los auditorios cautivos, han desplazado el pensamiento racional hacia "una óptica hedonista, adrenalínica, conductista y sensacionalista" (Se plantea que los deseos personales se debían satisfacer de inmediato sin importar los intereses de los demás). La seducción del mercado y la hipnotización social son la esencia del nuevo sistema mediático. Actualmente, los medios se han transformado en el poder supremo, el poder del poder que suplanta las funciones 
del Estado. Hoy por hoy, son el primer gran poder político-ideológico; han sustituido a la política y son los representantes reales de la voz y de la opinión de la sociedad. El Estado ha dejado de ser el regulador bajo el disfraz de la autorregulación de la industria, los medios se erigen como representantes sociales.

Estamos ante un nuevo Estado mediático que ya no es tan nuevo, ya en 1972 el libro de Dorfman y Matterlat "Para leer al Pato Donald" denunciaba el consumo comunicacional a través de las industrias culturales norteamericanas, quienes expanden sus valores burgueses a los mercados del sur, con un doble propósito. Por una parte, difundir la ideología capitalista, y los intereses de la clase dominante, como los valores predominantes en la sociedad, a fin de mantener el status quo que previene la rebelión proletaria. $\mathrm{Y}$, además, incentiva el consumo que, a la larga, permitirá que esa burguesía, expandan sus mercados. Ya para esa época, Disney como trasnacional del entretenimiento, viene imponiendo una gran carga ideológica, un estilo de vida consumista, que facilita y siembra el consumismo en la mente de los niños, de manera de reproducir las relaciones de explotación en el mundo y distraer a las masas oprimidas, desde la "supuesta" inocencia de los personajes infantiles.

\section{Medios de comunicación y socialización del consumo y sus valores}

Lo que hoy podemos afirmar que sea cual sea el modelo familiar y de escuela que tengamos, los medios de comunicación son un miembro activo dentro de estas, y el conflicto entre las dos miradas; la crítica que enfatiza el efecto negativo de la televisión sobre los hijos en formación valórica, que distorsiona la mirada infantil con violencia, sexualidad, consumismo y deterioro del desempeño escolar, por una parte, y la valoración de la televisión como medio que informa de modo eficiente, que une a la familia, que acompaña a los niños y constituye para ellos el principal medio de entretención. Estas dos miradas generan las dificultades que enfrentan los padres y maestros, a la hora de regular, tanto el tipo de programación como el número de horas de consumo televisivo por parte de los niños y niñas. Sobre todo las familias donde ambos padres trabajan y se ausentan de casa, la televisión es considerada como el compañero de juego, por tanto, ceden ante la presión de éstos para incorporar al nuevo amigo en el dormitorio, principal escenario de juegos y esparcimiento de los niños urbanos clase media.

La familia del siglo XXI, está cambiando, pero sigue siendo el primer factor de socialización de los individuos, aunque hoy esa socialización no garantiza el control social de hace unas décadas. La familia enfrenta una cantidad de retos: desarraigo, confrontación, delincuencia y conductas violentas de los jóvenes cuyos orígenes pudiesen estar vinculadas a su disfuncionalidad, desintegración, climas intensos de agresión, intolerancia, autoritarismo, falta de respeto, de afecto, etc. Situaciones que los medios electrónicos se empeñan en destacar y al parecer, la familia todavía no sabe cómo enfrentar, sobre todo porque muchos padres delegan a la 'niñera electrónica' la crianza sus los hijos.

Estadísticas recientes en Ibero América (2015), muestran que el consumo televisivo de los niños está en aumento, y que en algunos países, ya es mayor que el tiempo que ocupan en escuela y tareas, actualmente se encuentra en Colombia: 2 horas y 30 minutos, México: 4 horas 34 minutos, España: 2 horas 30 minutos, Alemania: 1 hora 33 minutos, Italia: 2 horas 49 minutos, Argentina: 3 horas 18 minutos. También señalan que la oferta para público infantil, es en un $74 \%$ de caricaturas. En el mercado mundial mediático, este género ocupa el séptimo lugar, en cuanto a lo transmitidos, detrás de programas de revista, noticiarios, películas, mercadeo, culturales y deportivos, de acuerdo con los Estudios Sobre Oferta y Consumo de Programación para Público Infantil en Radio, 
Televisión Radiodifundida y Restringida' (2015).

Tenemos entonces, una población infantil socializada para un consumo mediático que ha favorecido una condición trasnacional, estereotipada, occidentalizada, consumista y fragmentada. Que configura una identidad juvenil consumista, gráfica, dinámica, con "buenos sentimientos, orientación a la paz, ecológica, con poca diligencia para asumir verdaderas responsabilidades, poca capacidad para afrontar en primera persona la realidad, verdaderas obligaciones, sacrificada para construir algo duradero, deshabituada a reflexionar" (Hidalgo, Toledo, 2011).

Estamos ante una fragmentación comunicativa que acostumbra al televidente a ritmos elevados de incitación, ser víctima de un deseo continuo sin objeto, incapaz de soportar tensiones y hacer proyectos; con una debilidad de la voluntad, sentimentalismo, aburrimiento existencial e inmadurez despersonalizada, instrumentalizante, objetivadora. Sin compromiso, carente de sentido del pudor, factores que hacen exterior y superficial la intimidad, e impersonal la relación con los otros. Los medios y particularmente la televisión, desde los años 80, han exhibido la relación confidencial de la intimidad y se han colocado en el corazón de lo privado, exponiendo públicamente los sentimientos y las relaciones familiares $\mathrm{y}$ afectivas.

\section{CONCLUSIÓN}

Son diversas las opiniones la influencia los medios de comunicación sobre la violencia e inseguridad en los comportamientos de los adolescentes y jóvenes, creemos que hoy, hay una clara sobre exposición de los niños y adolescentes a la televisión y el cine, así como a formas más actuales, como los videojuegos e internet y sus youtuber. Varios estudios han revelado alguna asociación entre la introducción de la televisión con los aumentos en la escala de actos violentos, aunque la evidencia es discutible y no se ha comprobado su influencia en el largo plazo, la exposición a la violencia mostrada en la televisión aumenta las probabilidades de comportamientos agresivos inmediatos, además de enfatizar el consumo, de todo tipo, incluyendo alcohol y drogas.

Es por ello, que creemos al igual que los colegas Padilla, Padilla y Gamboa (2014) que ...hay que educar para la incertidumbre, permitiendo a las nuevas generaciones que asuman, ellas mismas en sus manos la construcción de una nueva sociedad. A la educación le correspondería de esta manera, proponer una nueva racionalidad y un nuevo sentido para las prácticas comunicativas. Al calor de las prácticas tecnoculturales, en especial la de niños, niñas y adolescentes, creemos de vital importancia promover la educación para los medios como maneras de leer de modo crítico y creativo, los discursos transmediáticos, para la promoción de audiencias conscientes de sus procesos mediacionales ante los medios de comunicación. (Padilla, Padilla y Gamboa, 2014)

Esta es la tarea y falta mucho por hacer pero ya estamos iniciando por eso, cada vez es más importante las acciones que tomamos desde la familia, la escuela y los Estados, para educarnos o mejor dicho, para obtener herramientas que nos permitan hacer un uso consiente de estos medios, para enseñar a las nuevas generaciones a consumir todos estos productos mass mediáticos, porque como ya sabemos Existen ideologías en el discurso que aparecen de manera explícita, estas son visibles y fáciles de detectar, pero cuando las ideologías se expresan de manera implícita o indirecta, escondida o menos obvia, es cuando ocupa su lugar el análisis crítico del discurso, todos esos discursos audiovisuales que transmiten estos medios masivos especialmente los dirigidos a niños, niñas y adolescentes, son los que requieren especialmente ese análisis de discurso crítico para poder desenmascarar las "supuestas NO 
ideologías o ideologías neutras" que facilitan cada vez más el desarrollo de sociedades violentas e inseguras.

\section{REFERENCIAS}

Briceño, León, Ávila Camardiel (2011). "Violencia e institucionalidad", Cajas Juan. CEPAL en el IV Seminario Iberoamericano de Ciencia y Tecnología.

Centro de Estudios Sociales (CES, 2009). Estudio Caracterización de la Violencia, Criminalidad e Inseguridad en Caracas: perspectiva comunitaria.

Cerna Cano, Julio (2002). Identidad, Cultura y Violencia Juvenil en el Perú y América Latina II Encuentro Metropolitano de Jóvenes Investigadores Sociales, UNMSM. Lima.

Dorfman A, Mattelart A. (1972). Para leer al pato Donald. Siglo XXI.

Hidalgo. (2011) Diagnóstico del consumo de drogas en el área de influencia del Cij Azcapotzalco. Centro de Integración Juvenil A,C. México

Hidalgo Toledo, J.A. (2011) Indicadores psicosociales del uso y consumo mediático - Slideshare es.slideshare.net/jhidalgo/indicadorespsicosociales-del-uso-y-consumomeditico may. 2011 - Ponencia presentada en el Encuentro Nacional de la Asociación Mexicana de Investigadores

Garrido, Gabriela (2009). Evangélicos en las cárceles chilenas: Rehabilitación Celestia. Disponible en: http://espanol.upiu.com/view/post/125 9073858104/

Guerra J. G. (2008). Exclusión de los jóvenes en Venezuela. Fundación Centro Gumilla. Observatorio de Participación y Convivencia Social Maestría CTS. (Inédito).

Instituto Nacional De Estadística (2009). Encuesta Nacional de Victimización. Caracas.

Ministerio Del Poder Popular Para Las Relaciones Interiores Y Justicia: Me $\neg$ moria y Cuenta 2010. p. 205.
Gran Misión A Toda Vida Venezuela (2012). Presentación ejecutiva

Consulta Ibero América (2015). Estudios Sobre Oferta y Consumo de Programación para Público Infantil en Radio, Televisión Radiodifundida y Restringida' disponible en

www.sej473.com/.../Programa\%20para \%20la\%20detección\%20del\%20consum o\%20de..

Nacional de Quilmes, Argentina: Curso de Sociología de la Tecnología, del Percepción de Seguridad Ciudadana (ENVPSC-2009). Caracas, 2011.

Padilla, Padilla, Gamboa. Coop (2014) .Caballos de Troya mediáticos cabalgan los aprendizajes implicaciones educativas de las prácticas tecnoculturales de niñas, niños $\mathrm{y}$ adolescentes en el contexto escolar. Ministerio del Poder Popular para la Educación informe especial sobre la consulta por la Calidad Educativa

Boaventura de Sousa, Santos (2009). Una epistemología del Sur. México.

Toledo (2011), Indicadores psicosociales del uso y consumo mediático. Disponible en http://www.slideshare.net/jhidalgo/indi cadores-psicosociales-del-uso-yconsumo-meditico

Vuanello, Roxana. (2005). Violencia e Inseguridad Urbana: La Victimización de los Jóvenes. Universidad Nacional de San Luis. Argentina.

Zambrano D., Luisa F. (2010). Estrategias que usan los medios para presentar el tema de la inseguridad ciudadana en Venezuela (parte I y II). Publicación disponible en www.aporrea.org.ve

Zambrano. D. Luisa F. (2012) Jóvenes, inseguridad y violencia desde el quehacer de los movimientos cristianos: Tecnologías sociales en tres iglesias de Caracas. Publicación de la Universidad Nacional Experimental de la Seguridad Unes.

Zambrano. D. Luisa F. (2017) Consumo, medios de comunicación y dominación. Una aproximación a partir de las apetencias de la clase media en el siglo XXI. Araca editores. Caracas 